\begin{abstract}
Der vorliegende Aufsatz unternimmt den Versuch, in einer vergleichenden Analyse die Prosatexte zweier zeitgenössischer serbischer Autoren hinsichtlich ihrer satirisch-komischen Erzählstrategien zu befragen. Die analysierten Texte von Svetislav Basara und David Albahari werden der serbischen Postmoderne zugerechnet und bieten sich aus thematischen wie auch narratologischen Gründen für eine Reflexion von Komik und Paranoia an. Besonders interessant wird der Vergleich dadurch, dass die Entstehungszeiträume und die politisch-historischen Kontexte der ausgewählten Texte unterschiedlich sind; deren Entstehungszeitraum reicht von Ende der 1980er bis zum Ende der 2000er Jahre. Die Prosatexte der beiden Autoren werden daher mit einem Fokus auf die unterschiedlichen Erscheinungen und Bedeutungen des Phänomens der Paranoia hin untersucht, das den strukturellen und thematischen Kern der Texte bildet. Daher werden im Beitrag zunächst einige kurze Vorüberlegungen zu Paranoia geboten. Darauffolgend wird eine Textanalyse der Romane vorgenommen, die das Verhältnis der Paranoia zu den komischen, ironischen und satirischen Aspekten der Texte in den Blick nimmt.
\end{abstract}

Key words: Komik, Paranoia, postmoderner Roman, Satire, David Albahari, Svetislav Basara

\title{
Das Textkorpus
}

Die in der vorliegenden Abhandlung analysierten Prosatexte zweier zeitgenössischer serbischer Autoren, David Albahari (g. 1948) und Svetislav Basara (g. 1953), stellen eine repräsentative Auswahl aus ihrem umfangreichen Werk dar. Im Fokus der Analyse befinden sich die Romane Mrak (1997), Pijavice (2005) und Ludvig (2007) von Albahari, sowie Basaras Romane Fama o biciklistima (1988) und das Diptychon Looney Tunes (1997) und Sveta mast (1998). Während die drastische Komik und satirische Absicht das literarische Schaffen Svetislav Basaras prägen, ist die Prosa David Albaharis durch eine subtile postmoderne Ironie gegenüber klassischen narrativen Strategien gekennzeichnet.

Fama o biciklistima (Die Verschwörung der Fahrradfahrer²), Basaras Kultroman aus den 1980 ern, ist ein Text über die letzten Jahre des sozialistischen Jugoslawien, der unmittelbar vor dem Zerfall des Landes erschienen ist. Der Roman hat die Form einer Sammlung realer und erfundener

1 Stipendista Austrijske akademije nauka (DOC-Fellow der ÖAW).

2 Die deutsche Übersetzung von Mascha Dabić, Berlin: Dittrich-Verlag 2014. 
Dokumente, angereichert mit Zeichnungen, echten und erfundenen oder gefälschten Zitaten, sowie realen oder retuschierten Fotografien. Der Erzähler bezeichnet sich als Herausgeber der Dokumentensammlung, er verwendet anstelle eines Namen die Initialen „S. B.“. Innerhalb der gesammelten Texte, welche ihrer Stilistik nach in verschiedenen literarischen Genres und in mehreren wissenschaftlichen Bereichen zu verorten sind, tauchen zahlreiche reale historische Persönlichkeiten, erfundene Gestalten und bekannte literarische Helden auf. Als Hauptprotagonist im Roman figuriert jedoch ein erfundener deutscher expressionistischer Dichter und Abenteurer namens Josef Kowalsky.

Looney Tunes und Sveta mast (Das heilige Schmalz) bilden gemeinsam Basaras satirisch-parodistisches Romandiptychon über die serbische Literaturszene der letzten drei Jahrzehnte des 20. Jahrhunderts, die Texte stehen daher im ideologischen Spannungsfeld zwischen Kommunismus und Nationalismus. Der gemeinsame Untertitel des Diptychons lautet „Manično-paranoična istorija srpske književnosti u periodu od 1979-1990. godine“ („Die manisch-paranoide Geschichte der serbischen Literatur im Zeitraum 1979-1990“). ${ }^{3}$ Der Ich-Erzähler in beiden Büchern ist die Figur Svetislav Basara, die zugleich der Hauptprotagonist ist. Er versucht eine Geschichte der serbischen Literatur zu verfassen, scheitert jedoch aus methodologischen Gründen ständig daran, da sich jedes Streben danach, eine objektive und allgemeingültige Geschichte zu schreiben, als aussichtslos erweist.

Den 1997 publizierten Roman Mrak (Die Dunkelheit) könnte man als Albaharis Vorgänger- und Vorbereitungstext für den Roman Pijavice betrachten. Der Text beinhaltet zwei voneinander getrennte Erzählstränge. Im ersten liegt der Fokus auf dem Verhältnis des Erzählers, der als Literaturübersetzer aus dem Englischen tätig ist und in Zemun wohnt, mit dem Agenten des staatlichen Geheimdienstes namens Davor Miloš. Bei ihrem ersten Zusammentreffen im Frühling 1985 versucht der Agent vom Erzähler mehr über einige Belgrader „Dissidenten“ aus den intellektuellen und künstlerischen Kreisen zu erfahren. In den nächsten Jahren nimmt Miloš gelegentlich immer wieder Kontakt mit dem Erzähler auf, was ihn zunehmend paranoid macht. Der zweite Erzählstrang kreist um die Beziehung des Erzählers mit seinem ehemaligen Schulfreund, dem Maler Slavko Radovanović. Slavko wird allmählich von dem paranoiden Gedanken besessen, dass der Erzähler heimlich eine Kunsttheorie aufgrund ihrer gemeinsamen Gespräche entwickelt. Dies begreift er als einen potenzieller Betrug bzw. künstlerisch-intellektuellen Diebstahl. Im Herbst 1989 - während in der Gesellschaft rund um die Protagonisten „alles zerfällt" (Albahari 1997: 33, 35) - lässt sich der Erzähler auf eine romantische Affäre mit Slavkos Frau Metka ein. Slavko wird 1991 vom serbischen Heer rekrutiert und in die Kriegsgebiete in Kroatien hingeschickt, während sich Metka der Antikriegsbewegung in Belgrad anschließt.

3 Obwohl gegen Ende des zweiten Buches eine weitere und abschließende Folge der Trilogie angekündigt wird, wurde sie nicht publiziert. 
2005 publizierte David Albahari Pijavice (Blutegel) ${ }^{4}$, ein Roman über die letzten Jahre des Regimes von Slobodan Milošević,- für den Albahari Thomas Pynchons The Crying of Lot 49 (1966) nachweislich als Vorbild nutzte. Der Ich-Erzähler des Romans ist ein einsamer Belgrader Journalist. Er beobachtet eines Tages, während seines rituellen Spaziergangs an der Donau, wie eine junge Frau von einem jungen Mann geohrfeigt wird. Dies löst eine Kette von verschwörerischen Geschehnissen aus, was den Erzähler paranoid werden lässt. Trotzdem gelingt es ihm, das geohrfeigte Mädchen Margareta zu finden. Sie gibt zu, dass der Erzähler von der geheimen Gesellschaft, welcher sie selbst angehört, absichtlich ausgewählt wurde, um an einem von ihnen geplanten kabbalistischen Experiment teilzunehmen. Das Experiment soll die serbischen Juden, sowie die serbische Gesellschaft im Allgemeinen vor Krieg und Hoffnungslosigkeit retten. Der Erzähler verlässt schließlich das Land, welches bald darauf, im März 1999, von der NATO bombardiert wird.

Der Roman Ludvig ${ }^{5}$ wurde 2007, unmittelbar nach Pijavice, veröffentlicht. Der Ich-Erzähler im Text, ein serbischer postmoderner Schriftsteller, erzählt vom Fall eines literarischen Betrugs, dessen Opfer er gewesen sein sollte. Sein ehemaliger bester Freund, ein dem realistischen narrativen Paradigma verpflichteter Autor namens Ludvig, soll angeblich dem Erzähler sein Konzept eines postmodernen Romans gestohlen haben. Den Roman veröffentlichte Ludvig unter seinem Namen, er gelangte mit dem Buch zu literarischem Weltruhm. Der Text des Romans stellt die Erinnerung des Erzählers an seine Ende der 1970er begonnene Freundschaft - und später Feindschaft - mit Ludvig dar, die sich allmählich in eine Art komisch-paranoide, groteske Obsession des Erzählers entwickelt hat.

\section{Was ist Paranoia und wie lässt sie sich erzählen?}

Paranoia wurde in theoretischen und literaturkritischen Auseinandersetzungen oftmals als eines der besonders charakteristischen Merkmale postmoderner Literatur hervorgehoben. Dabei wurde Paranoia üblicherweise als Symptom einer grundsätzlich anti-aufklärerischen, anti-rationalistischen Haltung der Postmoderne betrachtet. Einem paranoiden Weltbild entsprechen üblicherweise parodistische Versionen von Detektivgeschichten, eine umgekehrte Suche nach der Wahrheit oder der gescheiterte Versuch, ein Rätsel aufzulösen.

Typische Merkmale der Paranoia sind folgende: Eine Person unternimmt unter gewöhnlichen Lebensumständen eine Untersuchung, die aber über jedes vernünftige Maß hinausgeht. Ein Hauptprotagonist in Kriminalromanen handelt also wie ein Paranoiker, mit dem Unterschied, dass er von der Gesellschaft und von dem Staat als geistig ge-

4 Dt. Übers. von Mirjana und Klaus Wittmann: Die Ohrfeige. Eichborn, Frankfurt 2007.

5 Dt. Übers. von Mirjana und Klaus Wittmann: Ludwig. Eichborn, Frankfurt 2009. 
sund betrachtet wird. (Boltanski 2013: 46) Beide, der Detektiv und der Paranoiker bemühen sich, ein Rätsel, mit dem sie konfrontiert sind, aufzulösen. In diesem Sinn ähnelt ihre Tätigkeit soziologischen Untersuchungen. Boltanski dazu:

Wie der Kriminalroman und womöglich vor allem der Spionageroman stellt die Soziologie immer wieder die Realität der Realität auf den Prüfstand oder, wenn man das vorzieht, die vordergründig sichtbare Realität in Frage, um zu einer sowohl versteckteren, tieferen als auch realeren Realität zu gelangen. Und zwar indem sie sich ebenfalls auf die Identifizierung von Rätseln stützt, das heißt von Ereignissen oder Tatsachen, die der Realität zu widersprechen scheinen oder sich zumindest nicht leicht in das Bild integrieren lassen, das man gemeinhin verwendet, um dem, was geschieht, Sinn zu verleihen. (Boltanski 2013: 75)

Bei Sherlock Holmes oder Kommissar Maigret genügte die menschliche Vernunft um ein Rätsel aufzulösen, während bei den Paranoikern in den postmodernen Romanen von Pynchon, Basara und Albahari, die Vernunft kein ausreichendes Mittel mehr ist. ${ }^{6}$ Paranoia wird somit zur Nachfolgerin der Vernunft, wissenschaftliche Systeme werden durch Verschwörungsnarrative ersetzt. (Slade 1990: 226) Als Folge dieser „Dekonstruktion" der Vernunft, werden offizielle Versionen der Geschichte in Frage gestellt. Im nächsten Schritt kommt es zur Entstehung verschiedenen „alternativer“ Versionen, welche die Form einer Verschwörung oder eines Komplotts haben.

Das Problem der Paranoia ist immer mit Fragen nach der Normalität verbunden: Wer definiert die Normalität und garantiert für sie? Die „Normalität" von Basaras und Albaharis Protagonisten ist nämlich die gesellschaftlich-politische Lage, in welcher sich Serbien in den 1990ern befindet, eine Lage, worin das Absurde zur Normalität geworden ist. Im Winter 1989 auf 1990, nachdem Slavko aus Deutschland und Holland zurück nach Belgrad kommt, stellt der Albaharis Erzähler in Mrak folgendes fest: „Od sada, pomislio sam, merićemo naše postojanje pričama o tome kako je sa one strane. Nešto se podizalo između nas i te druge strane, nešto nevidljivo ali ipak dovoljno opipljivo i jako, i nikada više, ma gde se nalazili, nećemo moći da pređemo tu opnu od barijere." (Albahari 1997: 53) In Pijavice wird Serbien am Ende dieser Dekade ebenfalls als „verdrehte Welt" dargestellt (Albahari 2005: 28), als isolierte Insel oder eine "Aussätzigenkolonie, mit der niemand mehr etwas zu tun haben wollte“. (Ebd.: 73 [92]) Der Erzähler redet von einem „klebrigen Netz unserer Wirklichkeit, aus dem sich niemand befreien kann" (Ebd.: 28) und stellt ebenso fest, dass die „Nachahmung der Wirklichkeit“ wirklicher als die Wirklichkeit geworden sei. (Ebd.: 184)

6 „The Crying of Lot 49 represents a detective's nightmare, a world into which the substitution of radical ambiguity for truth transmutes individualism and self-reliance into narcissism, solipsism, and paranoia." (Patell 2001: 116) 
In den Tagen nachdem er die Ohrfeige und das mysteriöse Zeichen am Donauufer sieht (einen Kreis, in dem ein Dreieck eingezeichnet ist, in dem dann wiederum ein auf dem Kopf stehendes Dreieck steckt), stößt der Erzähler in Pijavice - genauso wie Pynchons Heldin Oedipa Maas wieder und wieder auf dieses Zeichen. Er beginnt an eine verdeckte Welt hinter der sichtbaren, an verborgene Ordnung und Sinn hinter den absurden und chaotischen Ereignissen zu denken. Er glaubt zu verstehen, dass nichts für sich allein existiert, dass alles miteinander verbunden und "Teil eines großen oder kleinen Netzes" ist. (Albahari 2005: 28, 44-45) Danach ist es für ihn nicht mehr möglich, dem Komplott zu entkommen. Für seinen Zustand verwendet er die Metapher eines Sumpfes, in welchem er versinkt. (Ebd.: 53) Die weiteren Geschehnisse erscheinen ihm zunehmend kompliziert und ungreifbar. Als er sich bemüht, die Sachen zu erklären, tauchen neue Lösungsmöglichkeiten auf. (Ebd.: 73) Er hat das Gefühl, in einen „gnadenlosen Wirbel, der wie ein Tornado alles aufsaugte" geraten zu sein. (Ebd.: 131 [Wittmann 2007: 167]) Damit wird ein Rätsel zur Verschwörungsgeschichte, und die Suche nach der Lösung des Rätsels wandelt sich in Paranoia. So stellt in einem späteren introspektiven Kommentar Albaharis Erzähler fest: „Wenn man eine Verschwörung wittert, kann praktisch alles ein Teil davon sein, man kann sie in jedem Ereignis und in jeder Erscheinung erkennen." (Ebd.: 159-160 [Ebd.: 205]) An anderer Stelle befragt er seine eigene Wahrnehmung auf paranoide Zustände hin: „Warum witterte ich plötzlich überall geheime Abmachungen, Zeichen, Verfolger und Verfolgte, Verschwörer und Irre?" (123 [157])

Sich an die Abhandlungen von Peter Knight anlehnend definiert Boltanski einen Komplott wie folgt: „Eine kleine Gruppe von mächtigen Leuten spricht untereinander heimlich die Planung und Durchführung einer illegalen und schädlichen Aktion ab, die sich auf den Gang der Ereignisse auswirkt.“" (Boltanski 2013: 362) Im Fall der Verschwörung in Pijavice sind aber die Menschen, die die Aktion planen, in politischer Hinsicht nicht mächtig, sondern gehören eigentlich einer unterdrückten Gruppe in der Gesellschaft an. Außerdem ist ihre Aktion, wie sie im Roman dargestellt wird, aus einer universal-humanistischen ethischen Hinsicht gesehen, nicht schädlich oder moralisch schlecht, sondern gerade umgekehrt. Im Unterschied zu klassischen Detektivgeschichten, wie sie von Boltanski beschrieben werden, ist der Staat bei Albahari keinesfalls eine moral- und sinnstiftende Instanz, die für die moralische Ordnung innerhalb der Gesellschaft sorgt. Gerade der Staat (Miloševićs Serbien) und die (serbisch-orthodoxe) Kirche werden als jene Machtstrukturen dargestellt, die im moralischen Sinne „schlecht“ sind. Die herrschenden politischen Strukturen sind korrumpiert und eng mit der organisierten Kriminalität verflochten. (Albahari 2005: 184-185) Mit ihrer Unterstützung agieren ultranationalistische, rassistische Organisationen, wie etwa die "Patriotische Armee der Einigkeit und des Heils“, mit ihren Fraktionen „Heil für alle“, die „Patrioten“ und die „Racheadler“ (Ebd.: 222-224), 
Organisationen, die vom Erzähler als „die Befürworter der Finsternis“ beschrieben sind. (Ebd.: 188) Es sind diese Gruppen, die verschiedene Verschwörungsszenarien erstellen und verbreiten, etwa Szenarien von einer Verschwörung der westlichen Welt gegen Serbien, also verschiedene Varianten serbischer Opfernarrative, wonach Serbien sich etwa „in den Klauen einer internationalen zionistischen Verschwörung" befindet. (Ebd.: 60)

Anhand des Schicksals Josef Kowalskys und anderer Protagonisten ${ }^{7}$ konstruiert Basara im Roman Fama o biciklistima eine Erzählung über den Geheimorden der Evangelischen Fahrradfahrer des Rosenkreuzes, die sich vom späten Mittelalter bis Ende des 20. Jahrhunderts erstreckt. Somit ist der Roman einerseits das Beispiel einer ironischen Haltung gegenüber der Unzuverlässigkeit von angeblich objektiver Geschichtsschreibung, andererseits entspricht die Geschichte der Paranoia-Auffassung von Richard Hofstadter, der in seinem oft zitierten Essay „The Paranoid Style in American Politics“ (1964) einen paranoiden Ansatz in Bezug auf politische und geschichtliche Themen wie folgt definiert:

The distinguishing thing about the paranoid style is not that its exponents see conspiracies or plots here and there in history, but that they regard a 'vast' or 'gigantic' conspiracy as the motive force in historical events. History is a conspiracy, set in motion by demonic forces of almost transcendent power. (Zit. nach Kuehl 1989: 232). ${ }^{8}$

Luc Boltanski vergleicht den klassischen Detektivroman - auf der Ebene des Erkenntnisinteresses - mit einer soziologischen Untersuchung. In postmoderner "Revision“ dieser literarischen Gattung aber, wo die Welt gänzlich „textualisiert“ wird, verwandelt sich die soziologisch interessierte Recherche in eine Untersuchung, welche man vielmehr mit Literaturwissenschaft und Philologie vergleichen könnte, und die nicht selten tatsächlich die Form einer solchen Untersuchung hat. Seiner gesamten Struktur nach wurde der Roman Fama o biciklistima als Nachahmung eines wissenschaftlichen Konvoluts aufgebaut, welches am Ende mit Appendix, Index und Inhaltsverzeichnis versehen wird. (Perišić 2007: 128) In diesem Sinne lässt sich der Text des Romans als ein Ergebnis einer wissenschaftlichen Recherche eines pa-

7 Beispielsweise König Karl der Grässliche und sein Majordomus Grossmann; der Kapitän Adam Queensdale sowie die spätere Kopisten und Verleger seiner Handschrift; der ratlose und besiegte Sherlock Holmes; Sigmund Freud und sein Patient Ernst Meier; der mysteriöse Geschäftsmann und Uhrenhasser Çulaba Çulabi, der einen besonderen Auftrag für den Architekten L. Loentze hat; die russischen Intellektuellen Kusnjetzow und Gribojedow als Lagerhäftlinge im Gulag; die in einem Konflikt stehenden Historiker und Kulturwissenschaftler Jurgis Baltrušaitis, Herbert Meier und D. H. Grainger; sowie der Schuster und Pseudophilosoph aus Tübingen Witold Kowalsky, der Vater des Hauptprotagonisten.

8 Dies ist genau der Punkt in welchem sich die parodistisch-satirische Intention in Basaras Fama o biciklistima mit Albaharis Pijavice überschneidet: Beide Texte untergraben und verlachen nämlich die verschiedenen „anti-serbischen“ Verschwörungstheorien, die in der serbischen Öffentlichkeit und im politischen Diskurs der 1990er gängig waren. 
ranoid gewordenen Forschers, d.h. des Herausgebers der Sammlung, lesen. Denn, wie es Niall Lucy formuliert, jedes theoretische System in den Geisteswissenschaften, jede systematisch entwickelte Interpretation der Welt könnte man als ein in sich geschlossenes, paranoides Weltbild betrachten. Lucy dazu:

A feature of paranoia is its potential to become a totalizing discourse, a discourse with no „outside“. For the paranoid, everything can count as evidence of a particular theory of the truth, a theory that is otherwise (from outside the space of paranoia, to which the paranoid is blind) understood to be grounded on a false assumption and so the "truth“ it sees is only a delusion based on a miscalculation or a misreading. But the theory itself, as a set of rules and procedures, is not necessarily wrong. (Lucy 1997: 13)

Von einer Detektivgeschichte kann im Albaharis Roman Pijavice nur bedingt die Rede sein, und zwar im Bezug auf die Anfangssegmente des Textes, später aber entwickelt sich der Text in eine hybride Form, die verschiedene Elemente von Phantastik und politischem Thriller umfasst. Der gesamte Romantext wurde zudem in einem Bernhard'schen „Mega-Paragraph" verfasst, wodurch die paranoide Suche des Protagonisten auch auf der graphischen Ebene des Textes herausgestrichen wird. Des Öfteren denkt der Protagonist darüber nach, ob die Realität - oder das, was ihm als Realität erscheint - lediglich seine Projektion sei, ein Ergebnis seiner eigenen Ahnungen, unbewussten Hoffnungen oder Vorurteile und Fehleinschätzungen. (Albahari 2005: 64, 123) Später ist er davon überzeugt, dass es zwischen der „Außenwelt" und der "Innenwelt“ keinen wirklichen Unterschied gebe, dass „die Außenwelt nur eine Projektion der Innenwelt" sei. (Ebd.: 228)

Dem paranoid-traumatisierten Ich-Erzähler und Hauptprotagonisten des Romans Mrak begegnet man vor einem leeren Papierblatt beim Verfassen des Textes über die Ereignisse, die zu Trauma und Paranoia geführt haben. Dabei versteckt er sich vor den Agenten des serbischen Geheimdienstes in einem Hotelzimmer in Kanada. Die Situation in welcher er sich befindet erlaubt ihm nicht, die Ereignisse - im bzw. durch den Text - zu „erklären“ (Albahari 1997: 10), was eine typische posttraumatisch paranoide Position ist, die keinerlei rationale und logische Erklärungen erlaubt. Bis zum Ende des Romans Ludvig - ganz ähnlich wie in The Crying of Lot 49 - bleibt dem Leser nicht bekannt, was eigentlich passiert ist, ob die Frau des Erzählers Ludvig getötet hat oder nicht, bzw. ob dies nur eine letzte paranoide Einbildung des Erzählers ist. Wie bei Pynchon bleibt das Weltbild des Romans innerhalb des eingeschränkten, unzuverlässigen Erkenntnishorizonts des Erzählers geschlossen.

9 Dies entspricht übrigens der klassischen psychoanalytischen Erklärung von Paranoia etwa in Freuds „Fall Scherbers“. (Dugdale 1990: 118-119) Paranoide Projektionen deutete Freud als Rückkehr des Verdrängten, „zensurierte“ Inhalte werden im Unbewussten umgewandelt und tauchen als „erfundene“ Geschichten wieder auf. (Ebd.: 143) 


\section{Komik der Paranoia, Paranoia als Komik}

Paranoia lässt sich also, wie gezeigt, als strukturierendes Muster des Erzählens in den Romanen von Svetislav Basara und David Albahari bezeichnen. Beim Ersten handelt es sich v. a. um eine Parodie der Geschichtsschreibung, beim Anderen ist die Paranoia auf den psychischen Zustand, in welchem sich die Erzählerfiguren in den Texten befinden, zurückzuführen. Bei beiden Autoren werden durch Paranoia unterschiedliche komische Effekte erzielt bzw. mehrere komische Stilmittel ${ }^{10}$ variert.

Wichtig ist es dabei, den Humor bzw. die Komik von der Satire abzugrenzen, denn Satire ist, wie Tom Kindt betont, zwar manchmal, aber nicht immer und ausnahmslos komisch, wie ja umgekehrt auch Komik bisweilen, aber keineswegs immer satirisch sein kann: „Beim Komischen handelt es sich um eine von verschiedenen Formen, in denen das Satirische auftritt; und das Satirische stellt eine von mehreren Funktionen dar, die das Komische haben kann." (Zit. nach Zymner 2017: 22) In seiner klassisch gewordenen Analyse der Satire hebt Northrop Frye Humor und Angriff als zwei der wesentlichsten Elemente jeder Satire hervor. Der satirische Humor sei dabei immer mit Phantastik, Groteske und Absurdität verbunden. Frye versteht Satire als „militante Ironie“ (Frye 1964: 227).

Die Texte von Basara weisen - weitaus deutlicher als jene von Albahari, die man vielmehr als ironisch bezeichnen könnte - einige prototypische satirische Aspekte auf. Sie sind „Ausdruck der Anstoßnahme an generellen, die Allgemeinheit betreffenden (tatsächlichen oder vermeintlichen, in den Augen des Satirikers gegebenen) Missständen oder Mängeln“, außerdem „eine Darstellung der Missstände oder Mängel“ und „zugleich ein Appell, diese Missstände abzustellen und diese Mängel zu beheben" (Zymner 2017: 21).

Die postmoderne Erzählpoetik Svetislav Basaras beruht einerseits auf der starken Ablehnung des mimetischen Darstellungsprinzips, auf seiner Parodisierung und Verhöhnung, andererseits fußt sie zugleich auf einer Beckett'schen Neigung zu logischen Widersprüchen sowie auf dem konstantem Untergraben des Rationalismus. Dazu kommen noch die unermüdliche Verspieltheit und Fröhlichkeit im Text, schwarzer Humor und Verspottung, die Persiflage verschiedener Fachsprachen und Erzählmanieren, der Einsatz von gefälschten und richtigen Zitaten, Erudition ebenso wie Simulation und Parodie des eruditiven Erzählens als Bestandteile der Poetik Svetislav Basaras. Im Hinblick auf Erzählmodelle und Strategien sind die Romane von Basara deutlich antimimetischer gestaltet als die Romane von Albahari. Chronologie und Kausalität werden bei Basara im Plotaufbau programmatisch aufgelöst. Die Textflächen im Roman werden zu einem Spielplatz für eine humorvolle Dekonstruktion

$10 \mathrm{Zu}$ den Grundbegriffen des Komischen zählen die Herausgeber des interdisziplinären Handbuchs Komik u.a. Humor, Witz, Ironie, Satire, Parodie, Komödie/Tragikomödie, Groteskkomisches, Sarkasmus usw. (Vgl. Wirth 2017) 
aller zeitlichen und räumlichen Gegebenheiten konventioneller Erzählung und Historiographie. Man könnte festhalten, dass gerade die komische Unfähigkeit des Erzählers, eine chronologisch geordnete und kausal entfaltende Erzählung zu schreiben, zu seinem „manisch-paranoiden“ Zustand geführt hat.

Der Roman Fama o biciklistima stellte einen Einschnitt in der Entwicklung von Basaras Prosa dar: Die Verlorenheit in der Sprache aus den früheren Werken des Autors wurde durch die „Verlorenheit“ in der Geschichte ersetzt. (Jerkov 2011: 132) Oder präziser gesagt: Die Verlorenheit im „reinen“ Text wurde durch die Verlorenheit in dem historiographischen Text ersetzt, was dann weiterhin zur narrativen Erstellung von paranoiden Verschwörungstheorien führte. Die zwei Literatursatiren Basaras hingegen könnte man als Beispiele „literaturhistoriographischer Metafiktion" bezeichnen (Rogač 2010: 77-83), ${ }^{11}$ sie basieren nämlich ähnlich wie Albaharis Ludvig - auf der „Verlorenheit“ des Erzählers im Text der Literaturgeschichte. Anders gesagt, Basaras Kultroman aus den 1980ern Fama o biciklistima stellte sich folgenden Fragen: Wer schreibt Geschichte, für wen und mit welchem Ziel? In Looney Tunes und Sveta mast, sowie in Ludvig und teilweise in Mrak, liegt das damit parallisierbare Hauptinteresse der Autoren auf den Fragen: Wer schreibt Literaturgeschichte, für wen und mit welchem Ziel? Wer bestimmt für wen und mit welchem Ziel den literarischen Kanon?

Basara geht in der Regel nicht auf die emotional-psychologischen Aspekte seiner Figuren ein, sie sind vielmehr als zweidimensionale Karikaturen gestaltet. Basaras Humor ist entfesselt: er ist direkt und aggressiv, typisch für das komische Repertoire bleiben ironischer Kontrast, Antithesen und Hyperbel, Wechsel zwischen Textsprache und Umgangssprache, Slapstick, Situationskomik, Sarkasmus, schwarzer Humor sowie Groteske.

Einige Theorien der Komik, wie z. B. die kanonisch gewordene Schrift Le rire (1900) von Henri Bergson, betonen, dass Komik auch mit Automatismus, Versteifung bzw. Mechanisierung in Zusammenhang steht (Müller-Kampel 2012: 18-19). Wenn man die drei hier besprochenen Texte von David Albahari vergleicht, zeigt sich bereits die Wiederholung der gleichen Erzählsituation in allen drei Romanen als komisch: Der Ich-Erzähler, der in einem paranoiden Zustand vor dem leeren Papierblatt sitzt und seine Geschichte mit der Hand - „unmittelbar" vor dem Leser - verfasst. Auf dieser narrativen Ebene ergibt sich jedoch eine Art Distanzierung der Protagonisten von ihrer eigenen Paranoia, oder besser gesagt, von ihrer eigenen Geschichte, und zwar in Form einer nachträglichen (Selbst-)Analy-

11 Die Bezeichnung von Rogač ist eine Ableitung des von Linda Hutcheon entwickelten Begriffes der historiographischen Metafiktion. Es geht laut Hutcheon um das eminent postmoderne Genre, das die Konstrukthaftigkeit historiographischer Texte bloßlegt und parodiert. Das Genre zeichnet sich in erster Linie dadurch aus, dass darin Elemente der öffentlichen, politischen Geschichte mit privaten, biographischen Erzählungen unentwirrbar miteinander verflochten werden. (Hutcheon 1988: 94-110) 
se. So empfindet etwa der Protagonist in Pijavice sein Schreiben wie einen Zustand, in dem eine „Verwechslung der realen mit der imaginären Ebene“ stattfindet und in dem es zu einem „Hin- und Herpendeln zwischen erdachten und realen Schichten" kommt. (Albahari 2005: 142 [Wittmann 2007: 182-183]) Zu einem „epistemologischen“ Durchbruch durch die Paranoia des Erzählers kommt es schon im ersten Satz des Romans:

Sada, šest godina kasnije, znam da je sve moglo drugačije da se odigra, ali tada, u nedelju, 8. marta 1998, kada je niz događaja o kojima nameravam da pišem počeo da se odvija, bilo kakva druga mogućnost dešavanja, osim one koja je upravo trajala, nije uopšte mogla da se zamisli. (Albahari 2005: 5) ${ }^{12}$

Aus zeitlicher Distanz kommentiert bzw. lacht der Erzähler über vergangene Ereignisse, sein eigenes Verhalten und seine damaligen Schlussfolgerungen, die nicht rational waren. Komik entsteht dadurch als Effekt der Reibung zwischen der erzählten und der erlebten Ebene im Text. Dies entwickelt sich in einem abwechselnden Spiel zwischen einer rationalisierenden, objektivierenden Reflexion und einer paranoid-verschwörerischen Haltung, nach welcher es keinen Zufall (in der Geschichte sowie im Leben) gibt bzw. geben kann.

Eine weitere rationalisierende Instanz innerhalb der Erzählung, die für komische Kontraste sorgt, stellen die Figuren wie Marko (Pijavice), Metka (Mrak) oder die Frau des Protagonisten in Ludvig dar. Man könnte sogar sagen, dass es im Fall Markos eigentlich um eine „Projektion“ des Erzählers geht, und dass Marko eine vernunftbezogene und hedonistische, zugleich aber „dunkle Hälfte“ des Ichs des Protagonisten personifiziert. (Albahari 2005: 90) Als der Erzähler durch Margareta von der Verschwörung erfährt, verschwindet Marko beinahe völlig aus dem Roman. (Ebd.: 273) In seinen viel zu nüchternen, „,anti-paranoiden“ und "anti-verschwörerischen“, meist eben arroganten und durchaus zynischen Kommentaren, spiegelt sich, in Form einer parodischen Rückwirkung, Albaharis ironisch geprägte Kritik des Rationalismus. (Ebd.: 20, 65, 180181) Ähnlich wie Marko lacht Metka die Gedanken des Erzählers aus, die sich auf Verschwörungstheorien beziehen: „Ništa je nije više zasmejavalo od priča o masonima, tajnim bratstvima i memorandumima, o svemu onome što je podrazumevalo zaveru. Takve priče najlakše omogućavaju, prezrivo je ponavljala, da se izbegne svaki osećaj odgovornosti prema životu." (Albahari 1997: 51) Die Verschwörung erscheint hierin als etwas, was die Romanfiguren zum Lachen bringt, sie wird zur Quelle von Komik innerhalb der erzählten Welt.

Das Verhältnis zwischen Slavko und dem Erzähler in Mrak basiert auf einem grundsätzlich komischen Missverständnis: Slavkos Misstrauen und Verdacht gegenüber seinem Schulkollegen beziehen sich auf die

12 „Heute, sechs Jahre danach, weiß ich, dass alles sich anders hätte abspielen können, aber damals, am Sonntag dem 8. März 1998, als der Reigen der Ereignisse, über die ich schreiben will, begann, war ein anderer Ablauf überhaupt nicht vorstellbar." (Wittmann 2007: 5) 
paranoide Angst, dass der Erzähler ihm seine - in der Realität nicht existierende - geniale Kunsttheorie stehlen wird, ${ }^{13}$ und nicht auf die Tatsache, dass er heimlich eine Liebesaffäre mit seiner Frau führt. Slavko ist dadurch in Zusammenhang mit der archetypischen komischen Figur des betrogenen Ehemann zu bringen, gleichzeitig auch teilweise mit dem „berauschten“ Künstler bzw. fürs alltägliche Leben inkompetenten Philosophen. Dazu könnte man ihn auch als einen eingebildeten, komisch-egomanischen Künstler betrachten (ein „Künstler im Versuch“), denn der Erzähler betont am Anfang, dass Slavko in der Tat nur ein Laienmaler ist. Slavkos Paranoia ist wiederum in Zusammenhang mit der Paranoia des Ich-Erzählers in Ludvig zu bringen, mit dem Unterschied, dass im zweiten Fall - aus offensichtlichen narratologischen Gründen - der Text restlos innerhalb des „epistemologischen“ Horizonts des Paranoikers geschlossen bleibt.

\section{Paranoia und Literaturgeschichte, Literatur der Paranoia}

Basaras Romane Looney Tunes und Sveta Mast sind als gesellschaftskritisch-politische Satiren zu verstehen. Allerdings sind das politische und literarische Feld im (post)jugoslawischen Kontext nicht voneinander zu trennen. Zwar ließen sich die Romane zum Teil auch als Parodien des Künstlerromans lesen, es gehören aber beide Werke auch zum Typus der sogenannten Literatursatire. Das ist - kursorisch zusammengefasst - „die satirische Bezugnahme eines Autors auf fremde Dichtungen und Dichter" (Zymner 2017: 24). Im Mittelpunkt der Geschichte befindet sich ein am Rand des damaligen literarischen Lebens in Serbien existierender Zirkel von Schriftsteller/-innen und Bohemiens. Die „philosophische“ Verlorenheit des Hauptprotagonisten in der oft paradoxalen Umgebung der spätsozialistischen Gesellschaft bietet Grund und Auslöser seiner „manisch-paranoiden" coming of age Geschichte. Beide Romanbände lassen sich deswegen auch als fiktionalisierte Erinnerungen Svetislav Basaras an seine ihn als Schriftsteller und Intellektuellen formierenden Jahre lesen.

Das heimische literarische Leben bzw. das literarische Feld, in dem Karrierismus und Opportunismus herrschen, wird satirisch entidealisiert und demythologisiert. Der Erzähler spricht vom „Pandämonium der serbischen Literatur“ (Basara 2009: 58). Reale, bekannte Autoren werden - mit einigen Ausnahmen - direkt oder mit leicht veränderten Namen genannt. In Opposition zu den Autor/-innen des Establishments befinden sich der Hauptprotagonist (namens Svetislav Basara) und mit ihm befreundete Autor/-innen, v. a. der montenegrinische Prosaist Miodrag Vuković sowie David Albahari). Das Hauptangriffsziel von Basaras

13 Die Kunsttheorie, die Slavko in seinen Bildern zu realisieren versucht - die sich aus mehreren im Text des Romans verstreuten Fragmenten rekonstruieren lässt - basiert auf einer Art Solipsismus, der einem paranoiden Weltbild sehr nahe steht. (Albahari 1997: 58) 
Literatursatire ist der einflussreichste serbische nationalistische Schriftsteller Dobrica Ćosić, der im Roman als „Veliki Disident“ (Der große Dissident) bezeichnet wird. Das Dissidententum Ćosićs im sozialistischen Jugoslawien wird als verlogen und opportunistisch dargestellt. ${ }^{14}$ So bildet sich eine klare ideologische Opposition innerhalb des literarischen Feldes heraus, worin die eine Seite für den sogenannten kritischen Realismus, Traditionalismus und vor allem für den Nationalismus steht. Die andere Seite, der sich Basaras Protagonist selbst zugehörig fühlt, vertritt dagegen den literarischen Modernismus und die Postmoderne, weswegen sie von der ersten Gruppe als anational und verräterisch angegriffen wird. Eine weitere Tätigkeit der Gruppe rund um Ćosić, die von Basara verspottet wird, ist das Herstellen und Verbreiten verschiedener angeblich antiserbischer Verschwörungsszenarien.

Als Gegenpol zu Ćosić wird Danilo Kiš dargestellt, und zwar als ein charismatischer literarischer Riese, umgeben von opportunistischen Zwergen (Basara 2010: 76). ${ }^{15}$ Die große Polemik, die Ende der 1970er in Jugoslawien rund um Kiš geführt wurde, wird bei Basara mitthematisiert (Basara 2009: 101f.). Hier wird der Angriff auf Kiš als eine Verschwörung des Großen Dissidenten und seiner Clique dargestellt.

Northop Frye warnt davor, dass „eine große Zahl von Satiren, die sich auf nationale Haßgefühle, Snobismus, Vorurteile und persönliche Ressentiments stützen, sehr schnell veralten" (Frye 1964: 228). Im Fall der hier besprochenen Texte - obwohl sie stark autobiographisch geprägt sind und ihre Figuren überwiegend auf realen Personen basieren - handelt es sich nicht um die Fiktionalisierung persönlicher Ressentiments gegen diese Autor/-innen, sondern es werden typisierte Figuren und Akteur/-innen innerhalb des literarischen Feldes dargestellt. ${ }^{16}$

Albaharis Mrak und Ludvig sind ebenfalls als Beispiele von Literatursatiren im serbischen Kontext der 1980er und 1990er Jahre zu verstehen und in diesem Sinne lassen sie sich als Pendants von Basaras Diptychon Looney Tunes und Sveta mast lesen. Das Hauptziel des satirischen Interesses in Mrak ist dabei der Einfluss der Schriftsteller auf die Entstehung des Nationalismus und somit ihre Verantwortung für die ideologische Vorbereitung des Krieges. (Albahari 1997: 91-98) Die Dokumentensammlung des Geheimdienstes, die er von Davor Miloš erhielt, bezeichnet der Erzähler als „zapisnik o ljudskoj dvoličnosti“ (Ebd.: 93), er redet ebenfalls von

14 Kritisch und satirisch schrieb Basara über Ćosić zudem in mehreren Zeitungskolumnen sowie in seinen Essays in den 1990ern, z.B. in seinem 1996 publizierten Essay „Virtuelni klasik“(„Der virtuelle Klassiker“; Basara 2008: 220-228).

15 Als zwei bahnbrechende Ereignisse der Epoche, die in Basaras Romandyptichon als „manisch-paranoid" bezeichnet wird (1979-1990), werden der Tod von Tito (1980) und von Danilo Kiš (1989) dargestellt.

16 Auch Pascale Casanova weist im Übrigen auf diesen Funktionsmechanismen hin, der Fall Danilo Kiš ist ihrer Interpretation nach als typisch für die sogenannten kleinen literarischen Felder zu betrachten (Casanova 2007: 108-115 u. 189-200). 
der „Kultur der Lüge“ (Ebd.: 133) wie von der herrschenden gesellschaftlichen Praxis in Serbien der 1990er Jahre. ${ }^{17}$ Die bizarr-komische Sexszene mit Svetlana, der angeblichen Mitarbeiterin des serbischen Geheimdienstes, stellt einen auf dem komischem Kontrast basierende Szene dar. Dem Erzähler wird klar, dass eine „Verschwörung“ - i.e. eine ideologische Mittäterschaft - im Zusammenhang der politischen Desintegration Jugoslawiens und des Bürgerkriegs, tatsächlich existiert bzw. existierte:

Pisanje je uteha (još nešto sam naučio). I paranoja je uteha. Postoji samo jedna stvar gora od uverenja da je sve povezano sa svim ostalim (i to sam negde pročitao), ${ }^{18}$ a to je pomisao da ništa nije povezano ni sa čim. U prvom uverenju može se proživeti život; sa drugim je raspad bića neminovan, čovek puca kao prenapregnuti balon. [...] Ostao sam bez poslednjeg utočišta, stajao sam na vatrometini, plutao sam u stvarnosti. Nije više bilo uverenja da postoji zavera, zavera jeste postojala, Davor Miloš je bio u pravu, neko je doista želeo da se desi sve što se desilo, i pisci su bili deo urote koja je imala svoje ciljeve. Šta hoću da kažem? Hoću da kažem da sam sve do večeras verovao da postoji mogućnost da su dokumenti u mom posedu lažni, da je istorija sila koja se događa izvan nas, nešto kao smena dana i noći ili preobražaj jednog godišnjeg doba u drugo, a ne rezultat dogovora, posledica sastanka kojem su prisustvovali namrgođeni (ili razdragani) članovi tajnog bratstva. (Albahari 1997: 91)

Am Beispiel des Verhältnisses zwischen dem Erzähler und Ludwig entwickelt Albahari eine satirisch gestaltete Geschichte der jugoslawischen bzw. serbischen Literatur der 1980er und 1990er. Obwohl die Figuren, im Unterschied zu Basara, erfunden sind, wird das serbische literarische Feld im Roman realitätsgetreu wiedergegeben, wie z. B. die Position und Bedeutung der Belgrader Zeitschrift Književna reč. In den 1970 ern und 1980ern war Ludvig nämlich ein Vertreter der sog. neorealistischen Prosa, während der Erzähler der Postmoderne zuneigte. Sein Durchbruchsroman - den er angeblich dem Erzähler gestohlen hatte schrieb er allerdings in postmoderner Manier. In den 1990ern, während des Krieges im ehemaligen Jugoslawien, unterstützte Ludvig die nationalistische Politik der damaligen serbischen Regierung und nahm aktiv an der Propaganda der Regierung teil, die die angebliche Verschwörung der ganzen Welt gegen Serbien verbreitete. Die Figur Ludvigs lässt sich als eine satirische Anspielung Albaharis auf den Schriftsteller Milorad Pavić

17 Einige Tage nach den großen Demonstrationen gegen die Regierung von Slobodan Milošević am 9. März 1991, übergibt Miloš dem Erzähler heimlich sein Dossier aus dem Archiv des Geheimdienstes, an dem er in den vergangenen Jahren gearbeitet hat. Einige Monate später, als der jugoslawische Bürgerkrieg im Sommer 1991 angefangen hat und Miloš angeblich den Dienst bereits verlassen hat und nach Zagreb gezogen ist, erhält der Erzähler per Post ein Paket mit den Dossiers von acht Personen aus den serbischen künstlerisch-intellektuellen Kreisen (i.e. von acht Schriftstellern), die in der Zwischenzeit politisch aktiv geworden sind. Unmittelbar nachdem er Kontakt mit einem Belgrader Journalist aufnimmt um die Dossiers zu veröffentlichen, wird in seine Wohnung eingebrochen und es werden seine Sachen durchgesucht.

18 Dies ist ein unmarkiertes aber wortgetreues Zitat aus Pynchons Gravity's Rainbow. 
lesen, bleibt aber - wie schon in Bezug auf die Literatursatiren Basaras erwähnt - in erster Linie eine allgemeingültige typisierte Karikatur einer charakteristischen Position innerhalb des serbischen literarischen Feldes der 1980er und 1990er Jahre. ${ }^{19}$ Auch die Obsession des Erzählers mit der serbischen Hauptstadt Belgrad, die als eine geschlossene, kleinbürgerliche, fremdenfeindliche und homophobe Umgebung dargestellt wird, ist als eine paranoide, satirische-groteske Hyperbel zu lesen.

Basaras Narration über den Geheimbund der Fahrradfahrer ersetzt die offizielle Geschichtsversion und liefert eine vollständige, aber „negative" allgemeine Geschichte der Zivilisation. ${ }^{20}$ Hier bricht die soziale Realität in den Roman ein, die wiederholten Anspielungen auf Titos Jugoslawien bringen eine historisch-ideologische Dimension in das an sich absurd-unterhaltsame Verschwörungsspiel. Der Roman ist eine versteckte, jedoch unmissverständliche Kritik an der kommunistischen Ideologie und eine satirische Entlarvung des sozialistischen Gesellschaftssystems und des totalitären Personenkults (Stalin, Tito). Der Geheimplan, an dem die Bruderschaft der Fahrradfahrer arbeitet, ist der Bau einer riesigen Krankenanstalt für 20 Millionen Geisteskranke - dort soll der Wahnsinn nicht länger verdrängt, sondern stattdessen für die Gesellschaft nutzbar gemacht werden: eine Metapher für das Jugoslawien der achtziger Jahre.

Albaharis Roman Pijavice, der nach dem Jugoslawienkrieg der 1990er spielt, bietet eine mögliche Antwort auf das Motiv der Irrenanstalt. Das Serbien aus den 1990ern wird hierin als ein Land dargestellt, welches aus der normalen Welt „exiliert“ wurde: „Der Irrsinn war nahe daran, zum Normalzustand erklärt zu werden", so der Erzähler. (Albahari 2005: 79 [Wittmann 2007: 99]) Im Frühling 1998, also jener Zeit, in der die Handlung im Roman spielt, begann die letzte Phase des Regimes von Slobodan Milošević. Die Kosovo-Krise erreichte ihren Höhepunkt mit dem NATO-Bombardment des Landes. Die schizoide Atmosphäre in der Gesellschaft wird im Roman widergespiegelt. ${ }^{21}$ Das mehrmals im Text erwähnte weiße Quadrat an der Wand in einem ehemaligen Gemeindebau in Zemun, wo früher das Bild Titos aufgehängt gewesen war, ist ein wichtiges Symbol des Romans. (Albahari 2005: 235, 238) Tito bleibt ein Gespenst, dessen Spuk das gesellschaftliche Leben immer noch entscheidend mitsteuert.

19 Ganz ähnlich ist auch die Figur Slavkos in Mrak als eine beinahe typische Laufbahn eines postmodern-alternativen Belgrader Künstlers aus den 1980ern zu verstehen, der Anfang der 1990er, als die politische Situation im Land sich allmählich radikalisiert, der Nationalismus wächst und der Krieg in Kroatien ausbricht, mehr und mehr in den nationalistisch-antisemitischen Rausch einfiel.

20 Mihajlo Pantić bezeichnet z. B. das Weltbild in Fama o biciklistima als eine „groteske Hyperbel der Welt“. (Vgl. Pantić 2011: 93-95)

21 Den Roman kann also als eine Allegorie für politische Entwicklungen im postkommunistischen Serbien verstanden werden. (Vgl. Rosić 2005: 134-135) 


\section{Fazit}

Jede versuchte allgemeine Kulturgeschichte des Lachens oder auch jede Komiktheorie hat wenig Anspruch auf Universalität, sie ist vielmehr eine Geschmacks- und Ideologiegeschichte. Komik kann also nicht in einer generalisierenden Theorie gefasst werden. Was als „komisch“ rubriziert wird, ist soziokulturell und historisch modelliert, Komik ist ebenso bildungs-, gruppen-, milieu- und klassenspezifisch wie alle kulturellen Praxen, und darum auch durchdrungen von Machtbeziehungen, Hierarchien und Autoritäten (vgl. Müller-Kampel 2012). Bei allen hier angestellten Überlegungen ist zu berücksichtigen, dass jene Textelemente, die hier in ihrer komischen Wirkung analysiert wurden, nur so wahrgenommen werden, wenn zumindest grundlegende Einigkeit hinsichtlich Normen / Konventionen und Werten vorherrscht, und wenn der Wissenstand bzw. die Erwartungshaltung ebenfalls zumindest grundlegend übereinstimmen (vgl. Frye 1964: 228).

In den hier analysierten Romanen hat der individuell-paranoide $\mathrm{Zu}-$ stand der Protagonisten eine weitreichendere politische Bedeutung und wird mit Komik bzw. Groteske angereichert. Die von Basara und Albahari verfassten gesellschaftskritischen Allegorien beziehen sich allerdings auf unterschiedliche Zeitpunkte. Basara schreibt über die Endphase des kommunistischen Jugoslawiens, während Albahari die Endphase der Regierung Miloševićs thematisiert, Pijavice ist vielmehr ein Roman über den Postkommunismus und über die postjugoslawische Gesellschaft. Das Hauptthema Basaras sind die Paradoxien der realsozialistischen Gesellschaft. Viele negativen Seiten des jugoslawischen Sozialismus stellen sich in seinen Literatursatiren jedoch nach der Erfahrung der Nationalismen und des daraus resultierenden politischen Zerfalls des Landes sowie der damit einhergehenden Kriege im Rückblick als deutlich weniger unerträglich heraus. Daher müssen die Diskuse rund um Literatur und den Literaturbetrieb bei Basara und Albahari als eine Art satirisch-allegorische Darstellung allgemeiner gesellschaftlicher Gegebenheiten im sozialistischen Jugoslawien und seinen Nachfolgestaaten verstanden werden.

\section{BIBLIOGRAPHIE}

Albahari, David (1997). Mrak. Beograd

Albahari, David (2005). Pijavice. Beograd

Albahari, David (2007). Ludvig. Beograd

Basara, Svetislav (2005 [1988]). Fama o biciklistima. Beograd

Basara, Svetislav (2009 [1997]). Looney Tunes. Manično-paranoična istorija srpske književnosti u periodu od 1979-1990. godine (Prvi deo). Beograd 
Basara, Svetislav (2010 [1998]). Sveta mast. Manično-paranoična istorija srpske književnosti u periodu od 1979-1990. godine (Drugi deo). Beograd

Basara, Svetislav (2008). Drvo istorije i drugi eseji. Beograd

Boltanski, Luc (2013). Rätsel und Komplotte: Kriminalliteratur, Paranoia, moderne Gesellschaft. Aus dem Franz. von Christine Pries. Berlin

Casanova, Pascale (2007 [1999]). The World Republic of Letters. Cambridge, Mass.

Dugdale, John (1990). Thomas Pynchon: Allusive Parables of Power. Basingstoke

Frye, Northrop (1964 [1957]). Analyse der Literaturkritik. Übers. v. Edgar Lohner und Hennig Clewing. Stuttgart

Hutcheon, Linda (1988). A Poetics of Postmodernism: History, Theory, Fiction. New York 1988.

Jerkov, Aleksandar (2011 [1998]). „Basarilo od Tormentsa ili Basaramazov“" in: Basara. Gradac. Časopis za književnost, umetnost i kulturu, br. 178179/god. 38/2011. Čačak

Kuehl, John Richard (1989). Alternate worlds. New York

Lucy, Niall (1997). Postmodern Literary Theory: An Introduction. Oxford

Müller-Kampel, Beatrix (2012). „Komik und das Komische: Kriterien und Kategorien“. In: LiTheS. Zeitschrift für Literatur- und Theatersoziologie 7, Graz, S. 5-39.

Pantić, Mihajlo (2011 [1994]). „Svetislav Basara: groteskna hiperbola sveta“ in: Basara. Gradac. Časopis za književnost, umetnost i kulturu, br. 178179/god. 38/2011. Čačak

Patell, Cyrus R. K. (2001). Negative liberties. Durham, NC

Perišić, Igor (2007). Gola priča. Beograd

Pynchon, Thomas (1967 [1966]). The Crying of Lot 49. New York

Rogač, Maja (2010). Istorija, pseudologija, fama. Beograd

Rosić, Tatjana (2005). „Pijavice u tami idiotske noći“. In: David Albahari. Gradac. Časopis za književnost, umetnost i kulturu, br. 156/god. 31/2005. Čačak

Slade, Joseph W. (1990 [1974]). Thomas Pynchon. New York

Wirth, Uwe (Hg.) (2017). Komik. Ein interdisziplinäres Handbuch. Stuttgart

Wittmann, Mirjana u. Klaus (2007) [Übers.]. David Albahari. Die Ohrfeige. Frankfurt am Main

Zymner, Rüdiger (2017). „Satire“. In: Wirth, Uwe (Hg.): Komik. Ein interdisziplinäres Handbuch. Stuttgart, S. 21-25. 
Горан Лазичић

Елена Меснер

Комичко и йараноја у йрози Давияа Албахарија и Светичслава Басаре

Резиме

У раду се упоредо анализирају романи два савремена српска аутора, Давида Албахарија (р. 1948) и Светислава Басаре (р. 1953), са фокусом на њиховим комичким и сатиричким наративним стратегијама. Корпус примарних текстова обухвата романе Мрак (1997), Пијавице (2005) и Луgвиі (2007) Давида Албахарија, као и романе Светислава Басаре Фама о бициклисииима (1988),

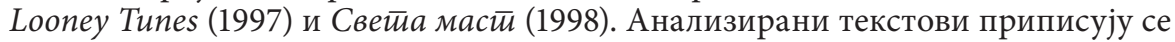
српском постмодернизму и нуде како на тематском плану, тако и у наратолошким аспектима прилику за промишљање међуодноса комике и комичке књижевности са феноменом параноје и теоријама завере. Полазна тачка у анализи су теоријски радови о феномену параноје (Luc Boltanski, Richard Hofstadter), као и књижевнотеоријска разматрања о односу тог феномена и постмодерне прозе (Niall Lucy). Текстови Албахарија и Басаре доводе се такође у везу са романима The Crying of Lot 49 (1966) и Gravity's Rainbow (1973) америчког постмодернисте Томаса Пинчона. Нарочита пажња посвећена је испитивању сатиричких аспеката текстова, јер се показује да је превасходна функција комике у анализираним романима управо сатиричке природе. Мета сатиричког интереса Албахарија и Басаре подједнако су друштвени токови и политичко-идеолошка питања, као и књижевно поље и међуоднос књижевности и политике, и то у турбулентном историјском периоду од почетка 1980-их до краја 2000их. Наративно различито испољени и функционализовани обрасци параноје и разуђени комички инструментариј у романима двојице аутора, указују се истовремено као одраз али и као коректив хибридно-шизоидне друштвене стварности на размеђи социјализма и постјугословенске транзиције.

Кључне речи: комичко, параноја, постмодернистички роман, сатира, Давид Албахари, Светислав Басара 